\title{
Identification of multi-drug resistant genes in $P$. aeruginosa isolates from patients under mechanical ventilation and respiratory support in an intensive care unit
}

\author{
Xiaoli Yang ${ }^{1}$, Hongping $\mathrm{Yao}^{2}$, Chun Zhang ${ }^{3}$, Cui $\mathrm{Li}^{1}$, Congying $\mathrm{He}^{1}$, Jinfang \\ Sheng ${ }^{1 *}$ \\ ${ }^{1}$ Shaanxi Institute for Food and Drug Control, Xi'an, 710065, ${ }^{2}$ Department of Pharmacy, ${ }^{3}$ Department of Surgical Intensive Care \\ Unit, The First Affiliated Hospital of Xi'an Jiaotong University, Xi'an 710061, China
}

*For correspondence: Email: jinfangsheng@hotmail.com; Tel: 0086-029-62288433

Revised accepted: 19 October 2018

\begin{abstract}
Purpose: To determine multi-drug resistant (MDR) and metallo $\beta$-lactamase (MBL)-resistant genes from Pseudomonas aeruginosa isolated from intensive care unit (ICU) patients under mechanical ventilation and respiratory support.

Methods: P. aeruginosa was isolated from 387 purulent tracheobronchial secretions collected from ICU patients who were intubated and mechanically ventilated for at least $48 \mathrm{~h}$. Antibiotic resistance was determined by minimum inhibitory concentration (MIC) assay while MDR genes, viz, blaTEM, blaOXA, blaVIM, blaCTX-M-15 were determined by polymerase chain reaction (PCR).

Results: A total of $144(37.2 \%)$ P. aeruginosa were isolated from the purulent tracheobronchial secretions. A majority of the isolates (51.4\%) were resistant to gentamicin. Meropenem-gentamicin was the predominant $(35.4 \%)$ resistant combination. Out of the 144 isolates, $102(70.8 \%)$ were positive for blaTEM gene, 51 (35.4\%) for were positive for blaOXA gene, 22 (15.3 \%) were positive for blaVIM gene, while 19 (13.2\%) were positive for blaCTX-M gene.

Conclusion: The high prevalence of MDR P. aeruginosa indicates the need for continued monitoring of $M D R P$. aeruginosa especially in ICU patients who are under mechanical respiratory support.
\end{abstract}

Keywords: Multi-drug resistance genes, Mechanical ventilator, Respiratory support, Pseudomonas aeruginosa

\begin{abstract}
This is an Open Access article that uses a funding model which does not charge readers or their institutions for access and distributed under the terms of the Creative Commons Attribution License (http://creativecommons.org/licenses/by/4.0) and the Budapest Open Access Initiative (http://www.budapestopenaccessinitiative.org/read), which permit unrestricted use, distribution, and reproduction in any medium, provided the original work is properly credited.
\end{abstract}

Tropical Journal of Pharmaceutical Research is indexed by Science Citation Index (SciSearch), Scopus, International Pharmaceutical Abstract, Chemical Abstracts, Embase, Index Copernicus, EBSCO, African Index Medicus, JournalSeek, Journal Citation Reports/Science Edition, Directory of Open Access Journals (DOAJ), African Journal Online, Bioline International, Open-J-Gate and Pharmacy Abstracts

\section{INTRODUCTION}

Mechanical ventilation is one of the fundamental elements of therapy for patients admitted in ICUs [1]. The ability of Pseudomonas aeruginosa to colonize in-patients is highly critical within ICUs. Mechanical ventilators used in the ICUs are associated with a higher risk of respiratory tract infections leading to ventilator-associated respiratory infections (VARI) and ventilatorassociated pneumonia (VAP) [1]. Pseudomonas aeruginosa is one of the most common organisms associated with nosocomial pneumonia [2]. According to the United States National Healthcare Safety Network (NHSN) 
data, $P$. aeruginosa was the second most common pathogen isolated from patients with VAP [2]. The National Nosocomial Infection Surveillance System (NNISS) in China reported that $P$. aeruginosa is the predominant pathogen isolated from the lower respiratory tract, accounting for $12.8 \%$ during 1999 to $2001,12.3$ \% during 2002 to 2004, and $13.4 \%$ during 2005 to 2007 period $[3,4]$.

A combination of $\beta$-lactams either with antipseudomonal quinolone or an aminoglycoside is the primary treatment choice for $P$. aeruginosa infections. However, increasing resistance towards various antibiotics has led to severe lifethreatening conditions which pose a challenge in the treatment of $P$. aeruginosa infections. Pseudomonas aeruginosa exhibits resistance towards multiple antibiotics leading to the development of multidrug-resistant (MDR) strains. The increase in MDR strains is a global problem. Multi-drug resistant $P$. aeruginosa strains are associated with increased morbidity and mortality, prolonged hospital stay, and higher costs of treatment [5]. Infections caused by resistant $P$. aeruginosa are often associated with excessive use of antibiotics, and invasive procedures including hemodialysis, tracheostomy and mechanical ventilation catheter [6].

Carbapenems were considered effective antibiotics against $P$. aeruginosa infections. However, due to extensive use of these antibiotics, the resistance mechanism spread across hospitals. Multi-drug resistance especially the MBL-producing strains has been commonly reported in all regions of the globe. The most common $\mathrm{MBL}$ genes are imipenem $(I M P)$, verona integron-encoded metallo- $\beta$-lactamase (VIM), Sao Paulo MBL (SPM), German imepenemase (GIM), and the recently reported Seoul imepenemase (SIM) families.

The true prevalence of MDR $P$. aeruginosa has not been well established mainly due to the ambiguity existing in the definition of MDR [5]. Different definitions of MDR have been used in the literature [7]. Majority of the published literature define MDR as strains which possess resistance to a minimum of three different antibiotic classes, mainly the anti-pseudomonal penicillins, aminoglycosides, fluoroquinolones, cephalosporins and carbapenems [5]. However, a group of experts from European Centre for Disease Prevention and Control and the Centers for Disease Control and Prevention, defined MDR as acquired non-susceptibility to at least one agent in three or more antimicrobial categories [7].
Strains are categorized as MDR strains based on the definition published by Magiorakos et al [7]. In addition, due to geographical variations and participating centers, the SENTRY antimicrobial surveillance program was developed to track antimicrobial resistance trends nationally and internationally, fail to report the true prevalence of MDR $P$. aeruginosa [8]. With the lack of safe therapeutic antibiotics against MDR and pandrug resistant strains, continued presence of such strains would pose serious challenges in infection control management [9]. Hence, it is extremely vital to understand the distribution of pathogens and antibiotic resistance patterns of pneumonia so as to achieve optimal antibiotic therapy. Although several studies have reported MDR $P$. aeruginosa, [5] limited data are available from China. The present study determined MDR resistant and $\mathrm{MBL}$ resistant genes from $P$. aeruginosa isolated from ICU patients who were under mechanical ventilation and respiratory support.

\section{EXPERIMENTAL}

\section{Sample collection}

A total of 387 purulent tracheobronchial secretions were collected from 387 non-repetitive patients who were admitted in ICU for various disabilities, and who were intubated and mechanically ventilated for at least $48 \mathrm{~h}$ between July 2015 and June 2017. Written informed consents were obtained from all the patients or their legal representatives after duly explaining the nature of the study. The study was approved by the institutional review board of The First Affiliated Hospital of Xi'an Jiaotong University, Xi'an, China (approval no. TKG155661) and was carried out as per WHO guidelines [10]. Samples were collected in a sterile container and sent immediately for microbial analysis. After collection, the samples were liquefied by the addition of $1 \% \mathrm{~N}$-acetyl cysteine (equal volume $\mathrm{v} / \mathrm{v}$ ) and homogenized by vortexing (3000 rpm for one $\mathrm{min}$ ). Then, $0.1 \mathrm{ml}$ of the sample was diluted (1:100 with $9.9 \mathrm{ml}$ of sterile physiological saline) and it was subjected to microbial culture [11].

\section{Isolation and identification of $\boldsymbol{P}$. aeruginosa}

The samples were sub-cultured onto MacConkey agar at $37^{\circ} \mathrm{C}$ for $18-24 \mathrm{~h}$. The non-fermenting, irregular, green-to-brown, catalase- and oxidasepositive colonies showing typical colony morphology of $P$. aeruginosa were subjected to identification using Vitek ${ }^{\circledR} 2$ microbial identification system (Vitek® 2 software, version R02.03, Advanced Expert System software, version $\mathrm{R} 02.00 \mathrm{~N}$ ). The isolates were stored in 
nutrient broth (with $20 \%$ glycerol) at $-40{ }^{\circ} \mathrm{C}$ until used for further analysis.

Minimum inhibitory concentration (MIC)
assay

The MICs of various antibiotics i.e. gentamicin, amikacin, piperacillin-tazobactam, ciprofloxacin, cefepime, ceftazidime, polymyxin $B$, imipenem and meropenem (Sigma-Aldrich, USA) against $P$. aeruginosa were determined. The inoculum was prepared by direct suspension of colonies grown overnight on nutrient agar in $0.85 \%$ saline, with turbidity adjusted to $0.5 \mathrm{McF}$ arland's standard for inoculation. The MIC assay (micro broth dilution method) was performed at concentrations of each antibiotic ranging from 0.03 to $128 \mu \mathrm{g} / \mathrm{mL}$; using Muller-Hinton broth (MHB) as described in Clinical Laboratory Standard Institute (CLSI) guidelines [12]. In essence, $10 \mu \mathrm{L}$ of culture was inoculated into the various concentrations of MHB and incubated at $37{ }^{\circ} \mathrm{C}$ for $24 \mathrm{~h}$. After incubation, MIC was determined visually by the highest concentration showing the absence of growth.

\section{Multiplex PCR}

DNA was extracted from pure cultures by alkali lysis method and stored at $-20^{\circ} \mathrm{C}$ until used for PCR. Multiplex PCR was used to determine extended-spectrum $\beta$-lactamases (ESBL)-MBL resistant genes such as bla $a_{T E M}$, bla $a_{O X A}, b / a_{C T X-M-}$

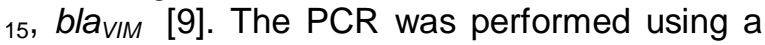
$50-\mu \mathrm{L}$ master mix containing $5 \mu \mathrm{L}$ of template DNA, 5 pmoL of each primer (Table 1), dNTPs (2 $\mathrm{mM}), 3$ units of Taq polymerase enzyme, $5 \mu \mathrm{L}$ of 10x reaction buffer, and molecular grade PCR water in a total volume of $50 \mu \mathrm{L}$. PCR was performed using the thermocycler (Applied Biosystems, Verti Thermal Cycler, Thermo Fisher Scientific). The PCR cycling conditions were: initial denaturation at $94^{\circ} \mathrm{C}$ for $5 \mathrm{~min}$ followed by 35 cycles at $94{ }^{\circ} \mathrm{C}$ for $30 \mathrm{~s} ; 56{ }^{\circ} \mathrm{C}$ for $30 \mathrm{~s}$, extension at $72{ }^{\circ} \mathrm{C}$ for $1.5 \mathrm{~min}$, and final extension at $72{ }^{\circ} \mathrm{C}$ for $7 \mathrm{~min}$. After PCR, amplicons were resolved in $1.2 \%$ agarose gel electrophoresis.

\section{Statistical analysis}

Continuous and categorical variables are presented as mean/ ranges and numbers/ percentages, respectively. ANOVA and chisquare tests were performed to determine the statistical significance using MINITAB statistical software (Minitab version 13.1; Minitab Inc, PA, USA). Values of $p<0.05$ were considered statistically significant.
Table 1: Primer sequence of ESBL-MBL resistant genes

\begin{tabular}{|c|c|c|}
\hline Gene & Primer sequence (5'-3') & $\begin{array}{l}\text { Amplicon } \\
\text { size (bp) }\end{array}$ \\
\hline blateM & $\begin{array}{l}\text { Forward: } \\
\text { TCAACATTTTCGTGTCGCCC } \\
\text { Reverse: }\end{array}$ & 766 \\
\hline laox & $\begin{array}{l}\text { AACTACGATACGGGAGGGCT } \\
\text { Forward: } \\
\text { AGATCCTTGACCCGCAGTTG }\end{array}$ & 928 \\
\hline & $\begin{array}{l}\text { Reverse: } \\
\text { CGCCGTCCCATCGAAAAATC } \\
\text { Forward: }\end{array}$ & \\
\hline blactx & $\begin{array}{l}\text { AGACTGGGTGTGGCATTGAT } \\
\text { Reverse: }\end{array}$ & 676 \\
\hline$-M$ & $\begin{array}{l}\text { TTAGGTTGAGGCTGGGTGAA } \\
\text { GT }\end{array}$ & \\
\hline$a_{v}$ & $\begin{array}{l}\text { Forward: } \\
\text { TGTCCGTGATGGTGATGAGT } \\
\text { Reverse: } \\
\text { GTGCTTCCGGGTAGTGTTGT }\end{array}$ & 456 \\
\hline
\end{tabular}

\section{RESULTS}

\section{Patients and isolates}

A total of 215 patients $(55.6 \%)$ were male, while 172 patients $(44.4 \%)$ were female (mean age $=$ $49.3 \pm 7.3$ years). Prior antibiotic therapy was given to 154 (39.8\%) patients. Out of the 387 purulent tracheobronchial secretions, 144 (37.2 $\%) P$. aeruginosa isolates were obtained, which was significantly higher than isolates of the other bacterial species $(p=0.02)$.

\section{Antibiotic resistance}

Amongst the $144 P$. aeruginosa isolates tested for antibiotic susceptibility, $74(51.4 \%)$ were resistant to gentamicin, 63 (43.8\%) were resistant to ceftazidime, $63(43.8 \%)$ were resistant to imipenem, $62(43.1 \%)$ were resistant to meropenem, $61(41.8 \%)$ were resistant to ciprofloxacin, $58(40.3 \%)$ were resistant to cefepime, $54(37.5 \%)$ were resistant to piperacillin-tazobactam, $35 \quad(24.3 \%)$ were resistant to amikacin, while $31(21.5 \%)$ were resistant to polymixin $\mathrm{B}$ (Table 2). No significant difference was found in the presence of antibiotic resistance among the isolates (ANOVA, $F=$ $0.00 ; p=1.00$ ).

A checkerboard analysis was performed to detect the cross-resistance of $P$. aeruginosa isolates to the related and unrelated antibiotics. The analysis showed that meropenemgentamicin was the predominant resistant combination observed in 51 (35.4\%) isolates. Other common resistance combinations included meropenem-ciprofloxacin (49, $34.0 \%)$, meropenem-ceftazidime $\quad(46, \quad 31.9 \%)$, 
ciprofloxacin-imipenem (46, $31.9 \%)$, ciprofloxacin-ceftazidime (43, $29.9 \%$ \%), meropenem-piperacillin/tazobactam (43, $29.9 \%$ ) meropenem-cefepime (42, $29.2 \%)$ and imipenem-cefepime (42, $29.2 \%)$ (Table 3). In addition, $58(40.3 \%)$ of the tested isolates were MDR strains.

\section{Resistance genes}

Out of the 144 isolates, $102(70.8 \%)$ were

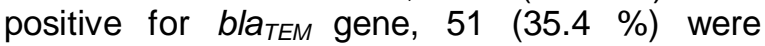
positive for bla oxa gene, 22 (15.3\%) were positive for bla $a_{V I M}$ gene, while 19 (13.2 \%) were positive for bla $a_{C T X-M}$ gene. The presence of blaTEM gene was significantly high among all the isolates tested by PCR $\left(X^{2}=138.07\right.$; $D F=3$; $p=0.00)$. However, no significant difference was found in the presence of resistance genes among the isolates which were resistant to various antibiotics (ANOVA, $\mathrm{F}=0.89 ; p=0.537$ ). Among these, bla $a_{T E M}-b / a_{O X A}$ was the most common gene combination in 17 (11.8\%) isolates, while bla OXA-bla $_{V I M}$, bla ${ }_{O X A}-b a_{C T X-M}$, bla $a_{T E M}-b / a_{O X A}-b / a_{C T X-M}$ were the second most common gene combinations detected in 4 (2.8 $\%)$ isolates.

Only one $(0.7 \%)$ isolate was positive for all four genes tested (Table 4). A comparison of antibiotic resistance and the presence of genes are shown in Table 5. Out of the 58 MDR isolates, 39 (67.2 \%) were positive for bla TEM $_{\text {TEM }} 32$ (55.2\%) were positive for bla OxA, 16 (27.6 \%) were positive for bla $a_{V I M}$, while 11 (19\%) were positive for bla isolates tested positive for any of the four tested genes. A total of 28 isolates which showed intermediate resistance towards the tested antibiotics were positive for bla $a_{T E M}(12)$, bla $a_{O X A}$ (8), bla $a_{C T X-M}(5)$ and bla $a_{V I M}(3)$ genes.

Table 4: MDR resistance genes among $P$. aeruginosa isolates

\begin{tabular}{lc}
\hline Gene & No of isolates (\%) \\
\hline blaTEM & $76(52.8)$ \\
blaOXA & $17(11.8)$ \\
blaVIM & $10(6.9)$ \\
blaCTX-M & $7(4.9)$ \\
blaTEM, blaOXA & $17(11.8)$ \\
blaTEM, blaVIM & $1(0.7)$ \\
blaOXA, blaVIM & $4(2.8)$ \\
blaOXA, blaCTX-M & $4(2.8)$ \\
blaTEM, blaOXA, blaVIM & $1(0.7)$ \\
blaOXA, blaVIM, blaCTX-M & $3(2.1)$ \\
blaTEM, blaVIM, blaCTX-M & $2(1.4)$ \\
blaTEM, blaOXA, blaCTX-M & $4(2.8)$ \\
blaTEM, blaOXA, blaVIM, blaCTX- & $1(0.7)$ \\
$M$ & \\
\hline
\end{tabular}

Table 2: Antibiotic resistance and MIC of $P$. aeruginosa isolates $(n=144)$

\begin{tabular}{|c|c|c|c|c|c|c|}
\hline \multirow{2}{*}{ Antibiotic } & \multicolumn{3}{|c|}{ No of isolates } & \multirow{2}{*}{$\begin{array}{c}\mathrm{MIC}_{50} \\
(\mu \mathrm{g} / \mathrm{mL})\end{array}$} & \multirow{2}{*}{$\begin{array}{c}\mathrm{MIC}_{90} \\
(\mu \mathrm{g} / \mathrm{mL})\end{array}$} & \multirow{2}{*}{ Range $(\mu \mathrm{g} / \mathrm{mL})$} \\
\hline & $\mathbf{S}$ & I & $\mathbf{R}$ & & & \\
\hline GN & 56 & 14 & 74 & 8 & 32 & $0.5-64$ \\
\hline CAZ & 62 & 19 & 63 & 16 & 128 & $2-128$ \\
\hline IPM & 73 & 8 & 63 & 2 & 64 & $0.25-64$ \\
\hline MEM & 72 & 10 & 62 & 1 & 32 & $0.5-64$ \\
\hline CIP & 69 & 16 & 61 & 2 & 8 & $0.06-8$ \\
\hline CPM & 72 & 14 & 58 & 8 & 64 & $\leq 0.03-\geq 128$ \\
\hline PTZ & 76 & 14 & 54 & 4 & $\geq 128$ & $8-\geq 128$ \\
\hline AM & 91 & 18 & 35 & 4 & 64 & $0.06-\geq 128$ \\
\hline POL & 95 & 18 & 31 & 1 & 32 & $0.06-64$ \\
\hline
\end{tabular}

Gentamicin (GN), amikacin (AM), piperacillin-tazobactam (PTZ), ciprofloxacin (CIP), cefepime (CPM), ceftazidime (CAZ), polymyxin B (POL), imipenem (IPM) and meropenem (MEM)

Table 3: Antibiotic cross resistance among $P$. aeruginosa isolates

\begin{tabular}{|c|c|c|c|c|c|c|c|c|c|}
\hline \multirow[b]{2}{*}{ Antibiotic } & \multicolumn{9}{|c|}{ No. of isolates } \\
\hline & GN & CAZ & IPM & MEM & CIP & CPM & PTZ & AM & POL \\
\hline GN & 74 & 32 & 24 & 51 & 35 & 35 & 27 & 30 & 22 \\
\hline CAZ & 32 & 63 & 29 & 46 & 43 & 28 & 39 & 29 & 19 \\
\hline IPM & 24 & 29 & 63 & 25 & 46 & 42 & 35 & 32 & 26 \\
\hline MEM & 51 & 46 & 25 & 62 & 49 & 42 & 43 & 26 & 17 \\
\hline CIP & 35 & 43 & 46 & 49 & 61 & 18 & 19 & 14 & 22 \\
\hline CPM & 35 & 28 & 42 & 42 & 18 & 58 & 26 & 24 & 25 \\
\hline PTZ & 27 & 39 & 35 & 43 & 19 & 26 & 54 & 23 & 16 \\
\hline AM & 30 & 29 & 32 & 26 & 14 & 24 & 23 & 35 & 18 \\
\hline POL & 22 & 19 & 26 & 17 & 22 & 25 & 16 & 18 & 31 \\
\hline
\end{tabular}


Table 5: Antibiotic resistance and MDR genes in $P$. aeruginosa isolates

\begin{tabular}{lcccc}
\hline Antibiotic & $\begin{array}{c}\text { blaTEM } \\
(\boldsymbol{n = 1 0 2})\end{array}$ & $\begin{array}{c}\text { blaOXA } \\
(\boldsymbol{n}=\mathbf{5 1})\end{array}$ & $\begin{array}{c}\text { blaVIM } \\
(\boldsymbol{n}=\mathbf{2 2})\end{array}$ & $\begin{array}{c}\text { blaCTX-M } \\
(\boldsymbol{n}=\mathbf{1 9})\end{array}$ \\
\hline GN $(\mathrm{n}=74)$ & 58 & 41 & 17 & 16 \\
CAZ $(\mathrm{n}=63)$ & 51 & 35 & 8 & 12 \\
IPM $(\mathrm{n}=63)$ & 48 & 25 & 12 & 6 \\
MEM (n=62) & 50 & 31 & 15 & 11 \\
CIP $(\mathrm{n}=61)$ & 32 & 23 & 8 & 5 \\
CPM (n=58) & 45 & 29 & 17 & 3 \\
PTZ (n=54) & 36 & 21 & 6 & 8 \\
AM $(\mathrm{n}=35)$ & 16 & 18 & 16 & 13 \\
POL $(\mathrm{n}=31)$ & 14 & 11 & 3 & 5 \\
\hline
\end{tabular}

\section{DISCUSSION}

Rapid and accurate identification of infectious agents is crucial for the initiation of appropriate therapy that has important consequences in patient's clinical outcome. It has been reported that rapid identification of infectious agents leads to a substantial reduction in the time taken to initiate effective antimicrobial therapy, and also decreases hospital cost and mortality [13]. Several studies have reported that Vitek ${ }^{\circledR} 2$ microbial identification system correctly identifies bacterial strains, with accuracy ranging from 85.3 - $100 \%$ [14 - 16]. In this study, rapid Vitek® 2 microbial identification system was used successfully to identify the isolates up to the species level.

The prevalence of $P$. aeruginosa was $37.2 \%$. A meta-analysis by Ding et al. [4] on 28 studies in China reported an overall $19.4 \%$ prevalence of $P$. aeruginosa in VAP, which is much lower than that obtained in the present study (37.2\%). Similarly, another systematic review from Mainland China reported that $20.6 \%$ of isolates from ICU patients with VAP were $P$. aeruginosa [17]. In other Asian countries, the prevalence of $P$. aeruginosa was much lower than that reported in this study, as indicated by these results: Thailand (18\%), Malaysia (18\%) and the Philippines (19\%) [18].

However, a study in Brazil reported a higher percentage $(51.9 \%)$ of $P$. aeruginosa isolates from ICU patients, when compared with the prevalence of $37.2 \%$ obtained in the present study. Studies have also reported that mechanical ventilator is a risk factor for $P$. aeruginosa infections [19]. A declining trend in the prevalence of $P$. aeruginosa isolates associated with VAP has been reported [4]. However, the present study obtained much higher percentage of $P$. aeruginosa than those reported in other Asian countries. This could possibly be due to the differences in periods of the studies. The Asian studies were conducted between 1999 and 2012. Thus, there could be fluctuations in the prevalence of $P$. aeruginosa over time, which may account for the differences in the prevalence figures. This variation in the prevalence implies that it is risky to adopt an attitude of complacence by continuing to refer to declining trend in the prevalence of $P$. aeruginosa in the Asian region based on previous findings. There should be a continuous monitoring system focused on $P$. aeruginosa infections in the clinical departments of hospitals, especially in the ICUs.

The inherent resistance of $P$. aeruginosa to a broad range of antibiotics, and its ability to develop MDR and acquired resistance through chromosomal mutations pose serious challenges during treatment $[8,16]$. Given the increasing resistance towards various antibiotics, MDR is expected to become more prevalent in several hospitals. In this study, $51.4 \%$ (MIC range: 0.5 $64 \mu \mathrm{g} / \mathrm{mL}$ ) of the isolates were found to be resistant to gentamicin, while only $24.3 \%$ (MIC range: $0.06 \geq 128 \mu \mathrm{g} / \mathrm{mL}$ ) of isolates were resistant to amikacin. Similarly, a meta-analysis in China reported gentamicin resistance in 51.1 $\%$ and amikacin resistance in $22.5 \%$ of the isolates in VAP cases [4].

A study in India reported comparable resistance $(18 \%)$ to amikacin, but much lower resistance values to gentamicin (38\%), ceftazidime (26\%), cefepime $(5.5 \%)$, meropenem $(18.5 \%)$, imipenem $(20.5 \%)$ and ciprofloxacin $(25.5 \%)$ [9], when compared to the $37.2 \%$ obtained in the present study. In contrast, a study in Romania reported higher resistance to amikacin (46.9\%), imipenem (49.8\%), piperacillin/tazobactam (49.7 $\%)$, meropenem (50.5\%), ceftazidime (53.1\%), ciprofloxacin (60.3\%) and gentamicin (64.2\%) [20]. Similarly, a study in Brazil reported higher antibiotic resistance for cefepime $(48.1 \%)$, imipenem (64.8\%), meropenem (64.8\%), piperacillin/tazobactam (46.3\%) and ceftazidime (63\%) [19]. In the present study, the highest resistance was to gentamicin $(51.1 \%)$, while the lowest resistance was to polymixin B $(21.5 \%)$. 
Extended spectrum $\beta$-lactamases are the major factor for acquired $\beta$-lactam resistance in $P$. aeruginosa -. In China, ESBL-producing $P$. aeruginosa isolates ranged from $35.3-64.7 \%$ which was higher than that reported from India (22.2 \%) [-21-23]. Among $\beta$-lactams, carbapenems (meropenem and imipenem) due to their stability against ESBLs are considered as the most potent agents for MDR $P$. aeruginosa [24]. In the present study, the activity of imipenem and meropenem were comparable, wherein $43.1 \%$ (MIC range $0.25-64 \mu \mathrm{g} / \mathrm{mL}$ ) of the isolates were resistant to imipenem and $41.8 \%$ (MIC range $0.5-64 \mu \mathrm{g} / \mathrm{mL}$ ) of isolates were resistant to meropenem.

A comparable resistance to imipenem (41.1\%) and meropenem (38.9 \%) was reported in China [4]. The study also reported comparable resistance values for ceftazidime (40.3\%), cefepime (38.5\%) and piperacillin/tazobactam $(38.9 \%)$, while a study in India reported much lower resistance $(25 \%)$ for meropenem and comparable resistance $(25 \%)$ for piperacillin/tazobactam [9]. In contrast, a study in Brazil reported much higher degrees of resistance $(64.8 \%)$ to meropenem and imipenem in $P$. aeruginosa isolated from ICU patients [19].Although the majority of the isolates were resistant to gentamicin, antibiotic resistance did not differ significantly among the isolates $(p=$ 1.00). In the present study, $40.3 \%$ of isolates were MDR strains, which is higher than that reported in Brazil (37\%) [19]. All the identified MDR isolates were resistant to gentamicin.

The ESBL enzymes encoded by TEM, CTX-M, GES, PER, SHV, VEB and IBC family of genes were prevalent among $P$. aeruginosa. In addition, OXA-type ESBL enzymes have been reported. The bla TEM $_{\text {gene }}$ was predominantly carried by $P$. aeruginosa, being narrow spectrum $\beta$ lactamases derived from mutation of single nucleotide from the TEM-1 and TEM-2, leading to TEM-3 and other variants which confer resistance to penicillin group of antibiotics. In this study significantly higher number of isolates $(70.8 \%)$ was positive for bla TEM gene. This is similar to current findings in a study in India which reported that bla TEM was the predominant gene present among the $P$. aeruginosa isolates (72.5\%) [9]. In that study [9], the bla $a_{O X}(33.5 \%)$ and blavim (11.5\%) genes were comparable.

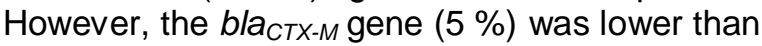
that the value obtained in the present study. In another study, $93 \%$ of the isolates were positive for bla ${ }_{O X A}$ gene which was much higher than that reported in the present study [16]. In $P$. aeruginosa, the bla OXA gene is considered a naturally occurring gene.
The high prevalence of this gene raises an alarm because this may lead to potential horizontal gene transfer where other co-inhabiting bacteria species may possess Class D $\beta$-lactamases. In one study [25], $19.6 \%$ of $P$. aeruginosa isolates were positive for bla ${ }_{C T X-M}$ gene, which is higher than that seen in the present this study. Although the presence of b/a TEM gene was significantly higher, the presence of resistance genes did not differ significantly among the isolates which were resistant to various antibiotics.

It has been reported that if an isolate was positive for bla $a_{C T X-M}$ gene but did not possess any of the other beta-lactamase genes, then the patient from whom the isolate was obtained can be treated using aminoglycosides, quinolones, carbapenems, and fourth and fifth generation cephalosporins, to the exclusion of cefotaxime and other third-generation cephalosporins [9]. In this study, a total of $7(4.9 \%)$ isolates which were positive for bla $a_{C T X-M}$ gene, did not amplify any of the other tested genes. The study [9] also reported that if an isolate showed presence of bla $a_{V I M I I M}, b / a_{T E M}$ and bla $a_{\text {CTX-M }}$ genes, the patient should be treated with colistin, polymyxin, aztreonam, or a combination of drugs [9]. In the present study, $2(1.4 \%)$ isolates were found to possess this combination of genes, which suggests that these patients should be treated with polymyxin, aztreonam, or a combination of drugs for better patient management.

\section{CONCLUSION}

$P$. aeruginosa is the predominant isolate from ICU patients under mechanical ventilation and respiratory support in this study. A majority of the isolates are resistant to gentamicin, and the predominant gene in the isolates is bla $a_{T E M}$. Compared to other studies, especially studies from Asia, the high prevalence of MDR $P$. aeruginosa indicates the need for continued monitoring of MDR $P$. aeruginosa especially in ICU patients under mechanical respiratory support.

\section{DECLARATIONS}

\section{Conflict of Interest}

No conflict of interest associated with this work.

\section{Contribution of Authors}

The authors declare that this work was done by the authors named in this article and all liabilities pertaining to claims relating to the content of this article will be borne by them. This study was 
designed by Xiaoli Yang, Hongping Yao, Congying $\mathrm{He}$, Jinfang Sheng. The data was acquired by Chun Zhang, Cui Li, Congying He, Jinfang Sheng. This study was supervised by Xiaoli Yang, Hongping Yao, Congying $\mathrm{He}$, Jinfang Sheng.

\section{REFERENCES}

1. Bobik $P$, Siemiątkowski A. Ventilator-associated pneumonia and other infections. Pneumonol Alergol Pol 2014; 82(5): 472-480.

2. Gaynes R, Edwards JR. National Nosocomial Infections Surveillance System. Overview of nosocomial infections caused by gram-negative bacilli. Clin Infect Dis 2005; 41(6): 848-854.

3. Wen XM, Ren $N$, Wu $A H, X u X H$. Distribution of pathogens causing nosocomial infection monitored by national nosocomial infection surveillance system and changing trend. Chinese Journal of Nosocomiology 2011; 21: 350-355.

4. Ding C, Yang Z, Wang J, Liu X, Cao Y, Pan Y, Han L, Zhan S. Prevalence of Pseudomonas aeruginosa and antimicrobial-resistant Pseudomonas aeruginosa in patients with pneumonia in mainland China: a systematic review and meta-analysis. Int $J$ Infect Dis 2016; 49: 119-128.

5. Hirsch EB, Tam VH. Impact of multidrug-resistant Pseudomonas aeruginosa infection on patient outcomes. Expert Rev Pharmacoecon Outcomes Res 2010; 10(4): 441-451.

6. Shorr AF, Tabak YP, Killian AD, Gupta V, Liu LZ, Kollef $M H$. Healthcare-associated bloodstream infection: $A$ distinct entity? Insights from a large U.S. database. Crit Care Med 2006; 34(10): 2588-2595.

7. Magiorakos AP, Srinivasan A, Carey RB, Carmeli $Y$, Falagas ME, Giske CG, Harbarth $S$, Hindler JF, Kahlmeter $G$, Olsson-Liljequist $B$, et al. Multidrug resistant, extensively drug-resistant and pandrugresistant bacteria: an international expert proposal for interim standard definitions for acquired resistance. Clin Microbiol Infect 2012; 18(3): 268-281.

8. Gales AC, Jones RN, Turnidge J, Rennie R, Ramphal R. Characterization of Pseudomonas aeruginosa isolates: occurrence rates, antimicrobial susceptibility patterns, and molecular typing in the global SENTRY Antimicrobial Surveillance Program, 1997-1999. Clin Infect Dis 2001; 32(Suppl 2): S146-S155.

9. Murugan N, Malathi J, Therese LK, Narahari $H$, Madhavan R. Application of six multiplex PCR's among 200 clinical isolates of Pseudomonas aeruginosa For the detection of 20 drug resistance encoding genes. The Kaohsiung $J$ Med Sci [internet] (Article in press; Available online 6 November 2017) 1-10. Available from: https://www.sciencedirect.com/science/article/pii/S1607 $551 \times 17303121$

10. International Ethical Guidelines for Health-related Research Involving Humans, Fourth Edition. Geneva.
Council for International Organizations of Medical Sciences (CIOMS); 2016.

11. Frota OP, Ferreira AM, Barcelos Lda S, Watanabe E, Carvalho NC, Rigotti MA. Collection of tracheal aspirate: safety and microbiological concordance between two techniques. Rev Esc Enferm USP 2014; 48(4): 618-624.

12. CLSI, M100-S25 Performance Standards for Antimicrobial Susceptibility Testing; Twenty-Fifth Informational Supplement An informational supplement for global application developed through the Clinical and Laboratory Standards Institute consensus process. 2015.

13. Goff DA, Jankowski C, Tenover FC. Using rapid diagnostic tests to optimize antimicrobial selection in antimicrobial stewardship programs. Pharmacother 2012; 32: 677-687.

14. Funke $G$, Monnet $D$, deBernardis $C$, von Graevenitz $A$, Freney $J$. Evaluation of the VITEK 2 system for rapid identification of medically relevant gram-negative rods. J Clin Microbiol 1998; 36(7): 1948-1952.

15. Jossart MF, Courcol RJ. Evaluation of an automated system for identification of Enterobacteriaceae and nonfermenting bacilli. Eur J Clin Microbiol Infect Dis1999; 18: 902-907.

16. Jaafar ZM, Dhahi MAR, Abd AKH, Jaafar SM. Molecular identification and antibiotics resistance genes profile of Pseudomonas aeruginosa isolated from Iraqi patients. Afr J Microbiol Res 2014; 8(21): 2183-2192.

17. Zhang Y, Yao Z, Zhan S, Yang Z, Wei D, Zhang J, Li J, Kyaw MH. Disease burden of intensive care unitacquired pneumonia in China: a systematic review and meta-analysis. Int J Infect Dis 2014; 29: 84-90.

18. Chawla R. Epidemiology, etiology, and diagnosis of hospital-acquired pneumonia and ventilator-associated pneumonia in Asian countries. Am J Infect Control 2008; 36(4 Suppl): S93-S100.

19. Matos EC, Matos HJ, Conceição ML, Rodrigues YC, Carneiro IC, Lima KV. Clinical and microbiological features of infections caused by Pseudomonas aeruginosa in patients hospitalized in intensive care units. Rev Soc Bras Med Trop 2016; 49(3): 305-311.

20. Gavriliu LC, Popescu GA, Popescu C. Antimicrobial resistance of Pseudomonas aeruginosa in a Romanian hospital at the dawn of multidrug resistance. Braz $J$ Infect Dis 2016; 20(5): 509-510.

21. Potron A, Poirel L, Nordmann P. Emerging broadspectrum resistance in Pseudomonas aeruginosa and Acinetobacter baumannii: Mechanisms and epidemiology. Int J Antimicrob Agents 2015 Jun; 45(6): 568-585.

22. Peshattiwar PD, Peerapur BV. ESBL and MBL mediated resistance in Pseudomonas aeruginosa: an emerging threat to clinical therapeutics. J Clin Diagn Res 2011; 5: 1552-1554.

23. Chen Z, Niu H, Chen G, Li M, Li M, Zhou Y. Prevalence of ESBLs-producing Pseudomonas aeruginosa isolates from different wards in a Chinese teaching hospital. Int $J$ Clin Exp Med 2015; 8(10): 19400-19405. 
Yang et al

24. Zavascki AP, Carvalhaes CG, Picão RC, Gales AC. Multidrug-resistant Pseudomonas aeruginosa and Acinetobacter baumannii: resistance mechanisms and implications for therapy. Expert Rev Anti Infect Ther 2010; 8(1): 71-93.
25. Polotto M, Casella T, de Lucca Oliveira MG, Rúbio FG, Nogueira ML, de Almeida MT, Nogueira MC. Detection of $P$. aeruginosa harboring bla CTX-M-2, bla GES-1 and bla GES-5, bla IMP-1 and bla SPM-1 causing infections in Brazilian tertiary-care hospital. BMC Infect Dis 2012; 12: 176. 